\title{
PENGARUH DESAIN PRODUK DAN PROMOSI TERHADAP KEPUTUSAN PEMBELIAN (Studi pada Konsumen Sepeda Motor Matic Yamaha FinoKecamatan Rimbo Bujang Kabupaten Tebo)
}

\author{
Isman, Jaya Laksana \\ Program Studi Manajemen Fakultas Ekonomi \\ Universitas Muara Bungo
}

\begin{abstract}
ABSTRAK
Penelitian ini bertujuanuntuk mengetahui pengaruh desain produk dan promosi terhadap keputusan pembelian. Populasi ini dalam penelitian ini sebanyak 66.830 jiwa dan sampelnya sebanyak 100 konsumen. Metode pengambilan sampelnya adalah purposive sampling. Metode analisis yang digunakan adalah analisis regresi linier berganda.

Berdasarkan hasil uji t menunjukkan bahwa variabel desain produkdan promosiberpengaruh berpengaruh signifikan secara parsial terhadap keputusan pembelian padakonsumen Sepeda Motor Matic Yamaha Fino Kecamatan Rimbo Bujang Kabupaten Tebo. Hasil uji F, menunjukkan bahwa desain produk dan promosi berpengaruh signifikan secara bersama sama terhadap keputusan pembelian padakonsumen Sepeda Motor Matic Yamaha Fino Kecamatan Rimbo Bujang Kabupaten Tebo.Dan hasil analisis regresi linier bergandadiperoleh persamaanyakniY $=4,163+0,627 \mathrm{X} 1+0,892 \mathrm{X} 2+\mathrm{e}$.

Berdasarkan nilai koefisien determinasi (R2) (adjusted R-square) yakni sebesar 0,679. Hal ini berarti bahwa desain produk (X1) dan promosi (X2) berkontribusi terhadap keputusan pembelian (Y) Sepeda Motor Yamaha Fino di Rimbo Bujang Kabupaten Tebo sebesar 67,9\%. Dan sisanya sebesar 32,1\% keputusan pembelian (Y) Sepeda Motor Yamaha Fino di Rimbo Bujang Kabupaten Tebo dipengaruhi oleh faktor-faktor lainnya di luar dari penelitian ini.
\end{abstract}

Kata Kunci: desain produk, promosi,keputusan pembelian

\section{PENDAHULUAN}

Pada era sekarang ini dimana tingkat persaingan dunia usaha di Indonesia sangat ketat, maka dari itu setiap perusahaan senantiasa berusaha untuk dapat meningkatkan pangsa pasar dan meraih konsumen baru. Suatu perusahaan harus bekerja keras membuat kebijakan-kebijakan strategis baru dalam menjual produk dan jasa mereka dalam kaitannya menghadapi persaingan yang ketat dengan kompetitor yang dapat memberikan value yang lebih besar kepada konsumen. Dalam meningkatkan persaingan masingmasing perusahaan harus dapat memenangkan persaingan tersebut dengan menampilkan produk yang terbaik dan dapat memenuhi selera konsumen yang selalu berkembang dan berubah-ubah (Kotler, 2009).

Pada dasarnya semakin banyak pesaing maka semakin banyak pula pilihan bagi konsumen untuk dapat memilih produk yang sesuai dengan harapannya. 
Tantangan yang dihadapi oleh perusahaan yang bersaingan diantaranya adalah selalu mendapatkan cara terbaik untuk merebut dan mempertahankan pangsa pasar. Maka dari itu, setiap pelaku usaha harus bisa menyusun dan mendesain suatu strategi yang nantinya mampu mendukung usahanya.

Tanpa strategi yang jitu perusahaan tidak akan dapat bertahan karena seiring waktu kompetitor akan terus muncul bersamaan dengan permintaan konsumen yang kian meningkat. Hal ini dihadapi oleh setiap perusahaan yang mencari laba dan tidak terkecuali industri sepeda motor.

Kebutuhan akan alat transportasi dewasa ini telah menjadi kebutuhan primer. Dibanding dengan alat transportasi umum, sebagian besar orang lebih memilih untuk menggunakan alat transportasi pribadi terutama sepeda motor guna menunjang aktivitas sehari-hari. Selain merupakan alat transportasi yang praktis dan lincah manakala digunakan untuk melewati kemacetan baik dalam kota maupun luar kota, konsumsi bahanbakar sepeda motor lebih rendah jika dibandingkan dengan kendaraan roda empat. Kemudahan kredit sepeda motor serta perilaku masyarakat yang cenderung konsumtif pun menambah jumlah pengguna sepeda motor dari waktu ke waktu.

Jika dilihat dari hasildataTop Brand Award Fase I Sepeda Motor Matic di Indonesia tahun 2020 pada tabel di bawah ini.

Tabel Data Top Brand Award Fase I Sepeda Motor Matic di IndonesiaTahun 2020

\begin{tabular}{|c|c|}
\hline Jenis Sepeda Motor Matic & TBI \\
\hline Honda Beat & $35,8 \%$ \\
\hline Honda Vario & $24,5 \%$ \\
\hline Yamaha Mio & $13,6 \%$ \\
\hline Honda Scoopy & $8,9 \%$ \\
\hline Honda PCX & $5,2 \%$ \\
\hline
\end{tabular}

Sumber: top-brand award.com (diakses, 16 Februari 2020)

Berdasarkan tabel di atas menunjukkan bahwa sepeda motor matic Yamaha Fino tidak termasuk lima besar pada Top Brand Award Fase I Tahun 2020. Sepeda motor matic Honda Beat tetap berada pada urutan ke satu dalam daftar Top Brand Award sepeda motor matic tahun 2020 fase satu denganpersentase 35,8. Kemudian diikuti urutan kedua yakni sepeda motor matic Honda Vario dengan persentase $24,5 \%$. Serta dirutan ketiga, keempat dan kelima yakni sepeda motor matic Yamaha Mio dengan persentase $13,6 \%$, sepeda motor matic Honda Scoopy dengan persentase $8,9 \%$ dan sepeda motor matic Honda PCX dengan persentase $5,2 \%$. Hal ini jelas bahwa Sepeda Motor matic Honda mendominasi pada pangsa pasar sepeda motor matic di Indonesia jika dibandingkan merek Yamaha yang akan menjadi tantangan bagi pabrikan Yamaha untuk lebih meningkatkan lagi kualitas produknya dan strategi 
pemasarannya sehingga diharapkan dapat meningkatkan lagi penjualannya yang secara tidak langsung dapat bersaing secara ketat dengan pabrikan Honda, khususnya pada pasar Indonesia.

Untuk lebih memperkenalkan produknya, perusahaan Yamaha gencar melakukan kegiatan promosi untuk menarik minat beli konsumen, diantara membuat iklan melalui media cetak ataupun elektronik, menyebarkan selebaran kepada masyarakat, mengadakan pertunjukan musik, mengadakan service gratis bagi pengguna sepeda motor Yamaha, dan lain-lain. Iklan didasari pada informasi tentang keunggulan dan keuntungan suatu produk, yang kemudian disusun sedemikian rupa sehingga menimbulkan ketertarikan pada yang melihat atau mendengarnya, dengan demikian iklan akan mempengaruhi perilaku pembelian konsumen terhadap suatu produk.

Pada tahun 2019 sepeda motor terlaris di Indonesia masih didominasi oleh sepeda motor matic. kontribusi penjualan tertingi, masih berasal dari segmen sepeda motormatic yang mencapai lebih dari $80 \%$ dari total penjualan roda dua di tanah air (otomotif.kompas.com, diakses 18 Februari 2020). Semuanya merupakan motor asal Jepang dan rata-rata merupakan motor buatan pabrikan Honda dan Yamaha. Kedua perusahaan otomotif tersebut saling berlomba menjadi yang terbaik di Indonesia. Tak heran apabila setiap motornya memiliki karakteristik yang sama. Padasepeda motor matic All New Honda Scoopy dan Yamaha Fino yang sama-sama menjadi sepeda motor matic dengan desain retro yang stylish. Rupanya penjualan kedua motor terlaris ini berbeda jauh, dan menempatkan sepeda motor matic Honda Scoopy menjadi yang terlaris. Nilai penjualan sepeda motor matic Honda Scoopy berkali-kali lipat lebih banyak dibandingkan sepeda motor matic Yamaha Fino. Padahal harga keduanya tidak berbeda jauh dan memiliki spesifikasi mesin berbeda. Apabila sepeda motor matic Yamaha Fino menggunakan mesin $125 \mathrm{cc}$, maka sepeda motor matic All New Scoopy setia memakai mesin $110 \mathrm{cc}$.

Sepeda motor matic Yamaha Fino bernuansa retro ini yang dibekali mesin 125 cc dengan teknologi Blue Core. Kemudian dipadukan dengan fitur SSS (Stop Smart System) yang berfungsi mematikan dan menghidupkan kembali mesin apabila sepeda motor berhenti lebih dari lima menit. Lewat SSS ini bisa menghemat konsumsi bahan bakar yang terbuang percuma saat dalam kondisi jalanan macet. Sepeda motor matic yang diciptakan khusus bagi perempuan ini hadir dengan ban bertapak lebar tipe tubeless berukuran 80/80-14M/C 43P di depan dan 100/70-14M/C 51P di belakang. Dengan ban lebar membuat pengendara menjadi semakin nyaman dan stabil berkendara di segala kondisi jalan.

Dalam upaya menarik minat konsumen dan meningkatkan penjualan, pada awal tahun 2020 PT. Yamaha Indonesia Motor Manufacturing (YIMM) kembali merilis tipe dan warna baru untuk sepeda motor matic Yamaha Fino yang terbagi dalam dua tipe yaitu sepeda motor matic Yamaha Fino Premium dan Fino Grande. Padasepeda motor matic Yamaha Fino Premium terdapat tiga pilihan warna baru, yaitu Brown, White, dan Black. Sedangkan sepeda motor 
matic Yamaha Fino Grande, mendapat dua varian warna, yaitu Blue dan Red. Pabrikan Yamaha sengaja menghadirkan warna-warna baru tersebut sebagai upaya mengikuti perkembangan life style masa kini.

Melalui sepeda motor matic Yamaha Fino yang cocok untuk semua kalangan khususnya anak muda yang aktif serta ingin menjadi trendsetter. Warna baru pada sepeda motor matic Yamaha Fino Premium terinspirasi dari wanita karir yang ingin tampil simpel dan tetap elegan saat berkendara. Sedangkan warnawarna yang ditawarkan ke sepeda motor maticYamaha Fino Grande terinspirasi dari wanita yang ingin tetap tampil elegan, berkelas, dan eksklusif saat berkendara.

Kemudian

perusahaan

Yamaha mempromosikan produk tersebut di Indonesia dengan berbagai cara baik dengan menggunakan tenaga penjualan, pemasaran langsung dari berbgai agen resmi Yamaha, diskon atau bonus-bonus yang akan diberikan. Dan juga melalui iklan dengan menggunakan media televisi, internet, spanduk atau brosur yang disebarkan ke masyarakat ke berbagai daerah di Indonesia.

Kecamatan Rimbo Bujang merupakan salah satu kecamatan yang paling padat penduduknya di Kabupaten Tebo Provinsi Jambi yakni sebanyak 56.830 jiwa (BPS tahun 2018) dengan didominasi etnis Suku Jawa, disusul Suku Melayu (masyarakat pribumi), Suku Minang, Suku Batak, Suku Sunda dan lainnya sehingga secara tidak langsung akan menjadi potensi pasar yang besar pada kebutuhan sepeda motor dalam upaya menunjang aktivitas seharihari masyarakat tersebut.

Berdasarkan observasi awal peneliti di lapangan yakni di CV. Aneka Motor (Sepeda Motor Yamaha) dan CV. Wulan Jaya (Sepeda Motor Honda) di Rimbo Bujang, dimana data penjualan sepeda motor pada tabel berikut ini.

Tabel Penjualan Sepeda Motor Yamaha dan Honda Pada CV. Aneka Motor dan CV. Wulan Jaya Rimbo Bujang Kabupaten Tebo dari Tahun 2017 - 2019

\begin{tabular}{|c|c|c|c|c|}
\hline \multirow{2}{*}{ Tahun } & \multicolumn{4}{|c|}{ Sepeda Motor (unit) } \\
\cline { 2 - 5 } & \multicolumn{2}{|c|}{ CV. Aneka Motor } & \multicolumn{2}{c|}{ CV. Wulan Jaya } \\
\hline & Yamaha & Yamaha Fino & Honda & Honda Scoopy \\
\hline 2017 & 630 & 38 & 1.533 & 803 \\
\hline 2018 & 548 & 29 & 2.009 & 567 \\
\hline 2019 & 564 & 31 & 966 & 418 \\
\hline Jumlah & $\mathbf{1 . 7 4 2}$ & $\mathbf{9 8}$ & $\mathbf{4 . 5 0 8}$ & $\mathbf{1 . 7 8 8}$ \\
\hline
\end{tabular}

Sumber: CV. Aneka Motor dan CV. Wulan Jaya Rimbo Bujang Kabupaten Tebo, 2020

Berdasarkan tabel bahwa pada tahun 2017 penjualan sebanyak 630 unit, tahun 2018 penjualan

dari tahun 2017 - 2019 jumlah penjualan sepeda motor Yamaha turun naik (berfluktuatif), dimana

sebanyak 548 unit dan tahun 2019 penjualan sebanyak 564 unit. Begitu juga pada penjualan sepeda motor 
Honda terjadi turun naiknya penjualan selama kurun waktu tiga tahun tersebut,dimana pada tahun 2017 penjualan sebanyak 1.533 unit, tahun 2018 penjualan sebanyak 2.009 unit dan tahun 2019 penjualan sebanyak 966 unit.

Kemudian jika dilihat dari penjualan sepeda motor matic Yamaha Fino dari tahun 2017 - 2019 jumlah penjualan sepeda motor matic Yamaha Fino berfluktuatif, dimana pada tahun 2017 penjualan sebanyak 38 unit, tahun 2018 penjualan sebanyak 29 unit dan tahun 2019 penjualan sebanyak 31 unit. Pada penjualan sepeda motor matic Honda Scoopy terjadi penurunan selama kurun waktu tiga tahun tersebut,dimana pada tahun 2017 penjualan sebanyak 803 unit, tahun 2018 penjualan sebanyak 567 unit dan tahun 2019 penjualan sebanyak 418 unit.

Berdasarkan penjualan secara keseluruhan sepeda motor matic Yamaha Fino dibandingkan dengan sepeda motor Honda Scoopy dari tahun ke tahun selama tiga tahun terjadi perbedaan penjualan yang signifikan, dimana penjualan sepeda motor matic Yamaha Fino lebih rendah dibandingkan penjualan sepeda motor matic Honda Scoopy. Hal ini bisa dimungkinkan dari pola strategi pemasaran yang diantaranya mengenai desain produk dan promosi dari pihak perusahaan Yamaha yang belum begitu baik dan tepat sasaran.

\section{Desain Produk}

Menurut Kotler dan Amstrong (2008), desain produk adalah jantung produk. Desain yang baik tidak hanya mempunyai andil dalam penampilan produk tetapi juga dalam manfaatnya. Kotler dan Keller (2009), desain produk adalah totalitas fitur yang mempengaruhi penampilan, rasa, dan fungsi produk berdasarkan kebutuhan pelanggan. Menurut Asshiddieqi (2012), desain produk adalah totalitas keistimewaan yang mempengaruhi penampilan dan fungsi suatu produk dari segi kebutuhan pelanggan. Dari sudut pandang perusahaan, sebuah produk yang didesain dengan baik akan mudah dibuat dan didistribusikan.

\section{Promosi}

Promosi adalah arus informasi atau persuatif satu arah yang dibuat untukmengarahkan seseorang atau organisasi kepada tindakan yang menciptakanpertukaran dalam pemasaran semua jenis kegiatan pemasaran yang mendorong permintaan (Swastha dan Irawan, 2008).Menurut Tjiptono (2008) promosi adalah suatu bentuk komunikasi pemasaran yang merupakan aktivitas pemasaran yang berusaha menyebarkan informasi, mempengaruhi/ membujuk, dan/atau meningatkan pasar sasaran atas perusahaan dan produknya agar bersedia menerima, membeli, dan loyal pada produk yang ditawarkan perusahaan yang bersangkutan.

Sedangkan menurut Santon dalam Sunyoto (2015), promosi merupakan unsur yang ada di dalam bauran pemasaran perusahaan yang kemudian didayagunakan untuk memberitahukan, membujuk, dan mengingatkan tentang produk perusahaan. Kemudian menurut Laksana (2008:133) promosi adalah suatu komunikasi dari penjual dan pembeli yang berasal dari informasi yang tepat yang bertujuan untuk merubah sikap dan tingkah laku pembeli, yang tadinya tidak mengenal menjadi mengenal sehingga menjadi pembeli dan tetap 
mengingat produk itu. Promosi ini merupakan komponen yang dipakai untuk memberitahukan dan mempengaruhi pasar bagi produk perusahaan.

\section{Keputusan Pembelian}

Setelah melalui tahap-tahap
proses keputuan pembelian, konsumen akan dihadapakan pada tindakan yang berujung pada keputusan konsumen untuk melakukan pembelian. Menurut Schiffman dan Kanuk (2010 dalam Sumarwan, 2011) merupakan suatu keputusan sebagai pemilihan suatu tindakan dari dua atau lebih pilihan alternatif. Keputusan pembelian adalah proses pengintegrasian yangmengkombinasikan

pengetahuan untuk mengevaluasi dua atau lebihperilaku alternatif dan memilih salah satu diantaranya (Peter dan Olson, 2000).

Kemudian menurut Kotler dan Armstrong (2008), keputusan pembelian adalah tahap dalam proses pengambilan keputusan pembelian dimana konsumen benar-benar membeli. Banyak faktor yang mempengaruhi perilaku komsumen dalam keputusan pembelian barang dan jasa. Keputusan pembelian yang dilakukan oleh konsumen tentu berdasarkan atas keinginan dan kebutuhannya terhadap suatu produk. Pada umumnya, keputusan pembelian konsumen adalahmembeli merek yang paling disukai (Kotler dan Amstrong, 2008).

\section{METODE PENELITIAN}

Penelitian ini menggunakan pendekatan deskriptif kuantitatif. Menurut Azwar (2008) penelitian deskriptif adalah suatu penelitian yang bertujuan untukmenggambarkan secara sistematik, akurat, dan karakteristik mengenai populasiatau mengenai bidang tertentu. Data yang dikumpulkan semata-mata bersifatdeskriptif sehingga tidak bermaksud untuk mencari penjelasan, menguji hipotesis, membuat prediksi atau pun mencari implikasi.Dengan kata lain, penelitiandeskriptif menekankan pada penyajian data secara sistematis dan akurat sehinggadapat memberikan gambaran dengan jelas.

$$
\text { Pendekatan kuantitatif }
$$

menurut Azwar (2008) adalah suatu penelitian yangmenekankan analisisnya pada data angka yang diolah dengan metode statistikatertentu. Dengan kata lain, penelitian menggunakan pendekatan kuantitatif jikadata yang digunakan bersifat angka.Pengambilan sampel dalam penelitian dilakukan dengan pertimbangan bahwa populasi sangat besar sehingga tidak memungkinkan untuk meneliti seluruh data yang ada karena memerlukan banyak biaya, waktu, dan tenaga. Oleh sebab itu, penelitian ini hanya menggunakan sebagian dari keseluruhan objek penelitian yang disebut sampel.

Teknik pengambilan sampel yang digunakan oleh peneliti adalah metode Purposive Sampling yaitu teknik penelitian sampel sumber data dengan pertimbangan tertentu (Sugiyono, 2015). Jadi jumlah sampel dalam penelitian ini sebanyak 100 responden.

Kriteria yang menjadi sampelnya adalah orang yang pernah membeli sepeda motor matic Yamaha Fino di dealer - dealer Yamaha di Kecamatan Rimbo Bujang Kabupaten Tebo dan usia responden minimal 17 tahun. 


\section{HASIL PENELITIAN DAN PEMBAHASAN}

\section{Uji t ( Parsial )} berikut ini.

Hasil Uji t pada model regresi linier berganda dari penelitian ini pada tabel

Tabel 4.31 Uji t Model Regresi Linier Berganda

Coefficients $^{\mathrm{a}}$

\begin{tabular}{|c|c|c|c|c|c|c|c|}
\hline \multirow[b]{2}{*}{ Model } & \multicolumn{2}{|c|}{$\begin{array}{c}\text { Unstandardiz } \\
\text { ed } \\
\text { Coefficients }\end{array}$} & \multirow{2}{*}{$\begin{array}{c}\begin{array}{c}\text { Standardize } \\
\mathrm{d} \\
\text { Coefficient } \\
\mathrm{S}\end{array} \\
\text { Beta } \\
\end{array}$} & \multirow[b]{2}{*}{ t } & \multirow[b]{2}{*}{ Sig. } & \multicolumn{2}{|c|}{$\begin{array}{c}\text { Collinearity } \\
\text { Statistics }\end{array}$} \\
\hline & B & $\begin{array}{l}\text { Std. } \\
\text { Error }\end{array}$ & & & & $\begin{array}{c}\text { Toleran } \\
\text { ce }\end{array}$ & VIF \\
\hline $\begin{array}{ll}1 & \text { (Constan } \\
& \text { t) }\end{array}$ & 4.163 & 1.256 & & 3.314 & .016 & & \\
\hline $\mathrm{X} 1$ & .627 & .1438 & .356 & 4.254 & .002 & .328 & 7.064 \\
\hline $\mathrm{X} 2$ & .892 & .259 & .327 & 3.398 & .000 & .328 & 7.064 \\
\hline
\end{tabular}

a. Dependent Variable: Y

Sumber : Lampiran 6(data diolah, 2020)

Hasil Uji tmodel regresi linier berganda pada tabel 4.31 menunjukkan bahwa nilai t-hitung variabel desain produk (X1) sebesar 4,254 dan variabel promosi (X2) sebesar 3,398. Kedua variabel ini masing-masing memiliki nilai $\mathrm{t}$ hitung yang lebih besar daripada nilai $\mathrm{t}$-tabel $=1,985$ pada tingkat signifikansi $(\alpha)=0,05$. Variabel desain produk (X1) dan variabel promosi (X2 yang masing-masing memiliki nilai

signifikansi $(\alpha)$ lebih kecil daripada nilai signifikansi $(\alpha)$ sebesar 0,05 . Dari kedua hal tersebut maka hipotesis nol ditolak dan hipotesis penelitian (Ha) diterima. Hal ini berarti bahwa desain produk (X1) dan promosi (X2) dari Sepeda Motor Yamaha Fino secara parsial berpengaruh signifikan terhadap keputusan pembelian (Y) Sepeda Motor Yamaha Fino di Rimbo Bujang Kabupaten Tebo

\section{Uji F} bawah ini.

Hasil Uji F model regresi linier berganda dari penelitian ini pada tabel di

Tabel 4.32

Uji FModel Regresi Linier Berganda

ANOVA $^{\mathrm{a}}$

\begin{tabular}{|c|c|c|c|c|c|c|}
\hline \multicolumn{2}{|c|}{ Model } & $\begin{array}{c}\text { Sum of } \\
\text { Squares }\end{array}$ & df & $\begin{array}{l}\text { Mean } \\
\text { Square }\end{array}$ & \multirow{2}{*}{$\frac{F}{59.723}$} & \multirow{2}{*}{$\frac{\text { Sig. }}{.000^{b}}$} \\
\hline 1 & Regression & 448.163 & 2 & \multirow{3}{*}{$\begin{array}{r}224.081 \\
3.752\end{array}$} & & \\
\hline & Residual & 363.908 & 97 & & & \\
\hline & Total & 812.071 & 99 & & & \\
\hline
\end{tabular}

a. Dependent Variable: Y

b. Predictors: (Constant), X2, X1

Sumber : Lampiran 6(data diolah, 2020) 
Hasil Uji F model regresi

linier berganda pada tabel 4.32 menunjukkan nilai F-hitung sebesar 59,723 dan nilai F-hitungnya lebih besar daripada nilai $\mathrm{F}$-tabel $=3,09$ pada tingkat signifikansi $(\alpha)=0,05$. Dari kedua hal tersebut maka hipotesis nol ditolak dan hipotesis penelitian (Ha) diterima. Hal ini berarti bahwadesain produk (X1) dan promosi (X2) dari Sepeda Motor
Yamaha Fino berpengaruh signifikan secara bersama sama terhadap keputusan pembelian (Y) Sepeda Motor Yamaha Fino di Rimbo Bujang Kabupaten Tebo.

\section{Koefisien Determinasi $\left(\mathbf{R}^{\mathbf{2}}\right)$}

Hasil perhitungan nilai koefisien determinasi pada model regresi linier berganda pada tabel berikut ini.

Tabel 4.33 Perhitungan Nilai Koefisien Determinasi Model Summary ${ }^{\mathrm{b}}$

\begin{tabular}{|l|c|r|r|r|}
\hline Model & R & R Square & $\begin{array}{c}\text { Adjusted R } \\
\text { Square }\end{array}$ & $\begin{array}{c}\text { Std. Error of } \\
\text { the Estimate }\end{array}$ \\
\hline 1 & $.829^{\mathrm{a}}$ & .683 & .679 & 1.58167 \\
\hline
\end{tabular}

a. Predictors: (Constant), X2, X1

b. Dependent Variable: Y

Sumber : Lampiran 7(data diolah, 2020)

Perhitungan nilai koefisien determinasi dari model regresi linier berganda pada tabel 4.33 menunjukkan bahwanilai koefisien determinasi $\left(\mathrm{R}^{2}\right)$ (adjusted $\mathrm{R}$-square) yakni sebesar 0,679. Hal ini berarti bahwadesain produk (X1) dan promosi (X2) berkontribusi terhadap keputusan pembelian (Y) Sepeda Motor Yamaha Fino di Rimbo Bujang Kabupaten Tebo sebesar 67,9\%. Dan sisanya sebesar $32,1 \%$ keputusan pembelian (Y) Sepeda Motor Yamaha Fino di Rimbo Bujang Kabupaten Tebo dipengaruhi oleh faktor-faktor lainnya di luar dari penelitian ini.

\section{PENUTUP}

\section{Kesimpulan}

1. Berdasarkan hasil Uji $t$ menunjukkan bahwa nilai $t-$ hitung variabel desain produk (X1) sebesar 4,254 yang lebih besar daripada nilai $\mathrm{t}$-tabel $=$ 1,985 pada tingkat signifikansi $(\alpha)=0,05$ dan memiliki nilai signifikansi $(\alpha)$ lebih kecil daripada nilai signifikansi $(\alpha)$ sebesar 0,05. Hal ini berarti bahwa desain produk (X1) dari Sepeda Motor Yamaha Fino secara parsial berpengaruh signifikan terhadap keputusan pembelian (Y) Sepeda Motor Yamaha Fino di Rimbo Bujang Kabupaten Tebo. Dan berdasarkan hasil Uji $t$ menunjukkan bahwa nilai $\mathrm{t}$ hitung variabel promosi (X2) sebesar 3,398 yang lebih besar daripada nilai $\mathrm{t}$-tabel $=1,985$ pada tingkat signifikansi $(\alpha)=$ 0,05 dan memiliki nilai signifikansi $(\alpha)$ lebih kecil daripada nilai signifikansi $(\alpha)$ sebesar 0,05. Hal ini berarti bahwa promosi (X2) dari Sepeda Motor Yamaha Fino secara parsial berpengaruh signifikan terhadap keputusan pembelian (Y) Sepeda Motor Yamaha Fino di Rimbo Bujang Kabupaten Tebo. 
2. Berdasarkan hasil Uji F menunjukkan nilai F-hitung sebesar 59,723 dan nilai Fhitungnya lebih besar daripada nilai $\mathrm{F}$-tabel $=3,09$ pada tingkat signifikansi $(\alpha)=0,05$. Hal ini berarti bahwa desain produk (X1) dan promosi (X2) dari Sepeda Motor Yamaha Fino berpengaruh signifikan secara bersama sama terhadap keputusan pembelian (Y) Sepeda Motor Yamaha Fino di Rimbo Bujang Kabupaten Tebo.

3. Berdasarkan nilai koefisien determinasi $\left(\mathrm{R}^{2}\right)$ (adjusted $\mathrm{R}$ square) yakni sebesar 0,679 . Hal ini berarti bahwa desain produk (X1) dan promosi (X2) dari Sepeda Motor Yamaha Fino berkontribusi terhadap keputusan pembelian (Y) Sepeda Motor Yamaha Fino di Rimbo Bujang Kabupaten Tebo sebesar $67,9 \%$. Dan sisanya sebesar $32,1 \%$ keputusan pembelian (Y) Sepeda Motor Yamaha Fino di Rimbo Bujang Kabupaten Tebo dipengaruhi oleh faktor-faktor lainnya di luar dari penelitian ini.

\section{Saran}

1. Disarankan bagi pihak Perusahaan Yamaha untuk meningkatkan desain produk Sepeda Motor Yamaha Fino dari segi model (style) agar lebih stylish lagi sehingga dapat diterima di semua kalangan atau lapisan masyarakat.

2. Disarankan bagi pihakdistributor atau dealer Sepeda Motor Yamaha Fino untuk lebih ditingkatkan promosinya dari segi penjualan personalnya (personal selling) dengan cara meningkatkan intesitas penawaran produknya kepada konsumen atau calon konsumen, seperti: promopromo yang diberikan, produk terbaru maupun kualitas yang dimiliki serta dengan kemudahan proses pengurusan pembeliannya.

3. Bagi penelitian selanjutnyadapat mengembangkan penelitian ini denganmenggunakan metode lain dalam meneliti desain produk, promosi dan keputusan pembelian, misalnya melalui wawancaramendalam terhadap responden, sehingga informasi yang diperoleh dapatlebih bervariasi daripada angket/kuesioner yang jawabannya telah tersedia.

\section{DAFTAR PUSTAKA}

Ansah, Ardi. 2017. Pengaruh Desain Produk, Promosi, Dan Citra Merek Terhadap Keputusan Pembelian Sepatu Nike Original Pada Pelanggan Sport Station Solo. Amwaluna: Jurnal Ekonomi dan Keuangan SyariahVol. 1 No.2 Hal 178189.

Asshiddieqi, Fuad. 2012. Analisis Pengaruh Harga, Desain Produk dan Citra Merek Terhadap Keputusan Pembelian. Diponegoro Journal Of Management, Volume 1, Nomor 1, Tahun 2012, Halaman 1-9.

Azwar, Ahmad, 2008, Metode Penelitian Suatu Pendekatan Praktik. Jakarta : Rineka Cipta. 
Carrisa A.S, Agustin Dwi. 2016. Pengaruh Desain Produk Dan Promosi Penjualan Terhadap Keputusan Pembelian Pada Sepeda Motor Yamaha Vega(Studi pada Siswa SMA di Wilayah Surabaya Timur). Jurnal Ilmu Manajemen (JIM)Vol. 4 No. 1.

Ferdinand, Agusty. 2011. Metodologi Penelitian Manajemen. Semarang: UNDIP.

Ghozali, Imam. 2011. Aplikasi Analisis Multivariat Dengan Program SPSS. Edisi Kelima. Semarang: BP. Universitas Dipenogoro.

Hidayah, Muhammad Rafli. 2017. Pengaruh Desain Produk dan Promosi terhadap Keputusan Pembelian pada Motor Sport Yamaha 150cc Di Kabupaten Klaten (Studi Kasus Pada Komunitas Motor Sport Yamaha 150cc Se-Kabupaten Klaten). Skripsi. Universitas Negeri yogyakarta.

Kotler, Philip. 2009. Managemen Pemasaran. Jakarta: Penerbit Erlangga.

Kotler, Philip dan Amstrong, Gary. 2008. Prinsip-Prinsip Pemasaran. Alih bahasa Bob Sabran M.M. Edisi Bahasa Indonesia. Jilid 1 dan 2. Jakarta: Erlangga.

Kotler, P dan Keller, Kevin Lane. 2009.

Manajemen

Pemasaran.Edisi Kedua Belas Jilid 1. Jakarta: Macanan Jaya Cemerlang.

2013. ManajemenPemasaran. Jakarta: Erlangga.

Laksana, Fajar. 2008. Manajemen Pemasaran. Edisi Pertama. Yogyakarta: Graha Ilmu.
Lembang, Roswita Dua. 2010. Analisis Pengaruh Kualitas Produk, Harga, Promosidan Cuaca Terhadap Keputusan Pembelian The Siap Minum Dalam Kemasan Merek Teh Botol Sosro. Semarang: Tesis Program Pasca Sarjana Magister Manajemen Universitas Diponegoro.

Pradana, Dhyto. 2016. Pengaruh Kualitas Produk, Harga, Promosi, Saluran Distribusi Dan Citra Merek Terhadap Proses Keputusan Pembelian Sereal Sarapan Nestle Koko Krunch (Studi Kasus Pada Pembeli Nestle Koko Krunch Di Wilayah Jakarta Selatan). Skripsi. Universitas Islam Negeri Syarif Hidayatullah. Jakarta.

Ridwan. 2012. Belajar Mudah Penelitian Untuk Guru, Karyawan, dan Peneliti Pemula. Bandung: Alfabeta.

Riyanto, Reza Puji. 2015. Pengaruh Brand Image, Promosi, dan Distribusi terhadap Keputusan Pembelian Sepeda Motor Honda Vario di Taruna Adiprima Motor Kudus. Skripsi. Universitas Negeri Semarang.

Raden Rara Ayu Widaningsih, Handoyo Djoko W, Sari Listyorini. 2014. Pengaruh Promosi, Desain Produk dan Kesadaran Merek terhadap Keputusan Konsumen Untuk Membeli Mobil Toyota Yaris (Studi Kasus pada PT Nasmoco Pemuda Semarang). Diponegoro Journal Of Social And Political Tahun 2014, Hal 1-10. 
Sanusi, A. 2013. Metodologi Penelitian Bisnis. Jakarta: Salemba Empat.

Sofjan, Assauri. 2011. Manajemen Pemasaran. Jakarta: Rajawali Pers.

Sunyoto, Danang. 2015. Perilaku Konsumen dan Pemasaran. Yogyakarta: CAPS.

Sumarwan, Ujang. 2011. Perilaku

Konsumen: Teori dan

Penerapannya dalam

Pemasaran. Bogor :Ghalia Indonesia.

Sugiyono. 2015. Metode Penelitian Kuantitatif dan Kualitatif dan $R \& D$. Bandung: Alfabeta.

Swastha, Basu dan Irawan. 2008. Manajemen

Pemasaran
Modern. Yogyakarta: Liberty Offset.

Swastha, Basu. 2010. Manajemen Pemasaran, Analisa Perilaku Konsumen. Edisi Pertama. Cetakan Ketiga Yogyakarta: Liberty.

Tanzeh, Ahmad. 2009. Pengantar Metode Penelitian. Yogyakarta: Teras.

Tjiptono, Fandy. 2008. Strategi Pemasaran. Yogyakarta: Andi Offset.

Zamroni. 2010. Pengaruh Kualitas Produk, Desain Produk dan Promosi terhadap Keputusan Pembelian Produk Elektronik Merek Polytron di Kabupaten Kudus. Skripsi. Universitas Negeri Semarang. 